\title{
Use of sap flow profiles in trunks to derive canopy conductance
}

\author{
A. Diaz-Espejo, J.E. Fernández \\ Instituto de Recursos Naturales y Agrobiología \\ IRNASE-CSIC \\ Apartado 1052, 41080-Sevilla \\ Spain
}

Keywords: olive, plum, orange, sap flow profiles, transpiration, stomatal conductance

\begin{abstract}
In this work we tested the hypothesis that if sap flow in the outer rings changes as a consequence of stomatal response to environmental variables, then we can infer canopy conductance from sap flow measurements. In 2004 we run experiments to calibrate the $t_{\mathrm{z}}$ compensation heat pulse method in three fruit tree species with contrasting hydraulic characteristics and water requirements: olive, plum and orange. In some of those experiments one tree of each species was cut at ground level and the butt placed in a reservoir with an adequate solution. Then we measured the actual tree transpiration $\left(E_{\mathrm{p}}\right)$ every half hour, as well as the total leaf area. The $E_{\mathrm{p}}$ values, together with simultaneous measurements of micrometeorological variables over the trees, were used to calculate reliable values of canopy conductance by inverting the P-M equation $\left(G_{c}\right)$. We also obtained independent values of canopy conductance from leaf gas exchange measurements carried out in the three instrumented trees $\left(g_{c}\right)$, and checked that they were similar to the $G_{c}$ results. Our $g_{c}$ data were compared to $t_{\mathrm{z}}$ profiles recorded in the trunk to test our hypothesis that the diurnal pattern of $t_{\mathrm{z}}$ profiles can be used to derive reliable values of canopy conductance. Results from the three tested species showed a good correlation between $t_{\mathrm{z}}$ and $g_{\mathrm{c}}$.
\end{abstract}

\section{INTRODUCTION}

Using the Penman-Monteith $(\mathrm{P}-\mathrm{M})$ model to derive tree transpiration $\left(E_{\mathrm{p}}\right)$ faces two main challenges: determination of total leaf area and determination of canopy conductance. In this work we have investigated a new approach based on sap flow measurements to obtain reliable diurnal trends of canopy conductance $\left(G_{\mathrm{c}}\right)$. Radial sap flow in tree trunks has been a matter of study in many works since a long time (Swanson, 1965; Čermák et al., 1982; Dye et al., 1991). The implications of the radial heterogeneity of sap flow density are being increasingly considered in recent publications (Čermák et al., 2008; Tateishi et al. 2008; Fiora and Cescatti, 2008). In addition to differences in the pattern of sap flow due to different conducting systems (ring-porous $v s$. diffuse porous), sap flow profiles have been reported not be constant with time, but change diurnally and seasonally (Fernandez et al., 2001). Changes in radial sap flow patterns have been attributed to the effect of water stored in the inner sapwood (Ford et al. 2004), to an increase of inner sap flow to compensate for cavitation in the outer rings (Poyatos et al. 2007), to stomatal closure in the exposed foliage (Fernández et al., 2001), to the vertical distribution of foliage in the crown (Fiora and Cescatti, 2008), or to the increase in the inner sap flow density with the water uptake from deep roots (Nadezhdina et al., 2007; 
Čermák et al., 2008). It can be concluded from those observations that the outer sapwood is mainly related to shallow roots and exposed new foliage, and that the inner sapwood is preferably connected to deep roots and shaded old foliage. Our working hypothesis is that if sap flow in the outer xylem changes as a consequence of stomatal response to environmental variables then we can infer canopy conductance from sap flow measurements. We tested this hypothesis in three species, olive, plum and orange, by using data from calibration experiments of the $t_{\mathrm{z}}$ compensation heat pulse method (CHP) (Fernandez et al., 2006). The advantages of the used data sets are: 1) we know the actual transpiration rate; 2) we know the actual total leaf area; 3) we have a good estimation of canopy conductance $\left(g_{\mathrm{c}}\right)$ from leaf gas exchange data.

\section{MATERIALS AND METHODS}

In the spring of 2004, a set of experiments was performed to calibrate the CHP method, as described by Green et al. (2003), for olive, plum and orange trees. An excision experiment was carried out for each species. Each tree was instrumented with three sets of sap flow probes. Each probe consisted of one heater and two temperature probes, installed downstream and upstream the heater. Each temperature probe had four thermocouple sensors at 5, 15, 25 and $40 \mathrm{~mm}$ below the cambium. Heat pulses were fired every $30 \mathrm{~min}$ (see Fernandez et al., 2006, for details on the measurements). We used the recorded values of the time delay for the temperature at points downstream and upstream from the heater $\left(t_{\mathrm{z}}\right)$ to obtain a proxi for transpiration

$$
E_{\mathrm{p}} \approx 1 / t_{\mathrm{Z}}
$$

In canopies well coupled to the atmosphere, reasonably good estimations of $E_{\mathrm{p}}$ can be obtained (Jones 1992; Tognetti et al., 2005) by assuming

$$
E_{\mathrm{p}} \approx G_{\mathrm{c}} \mathrm{VPD}
$$

and therefore,

$$
G_{\mathrm{c}} \approx 1 /\left(t_{\mathrm{z}} \mathrm{VPD}\right)
$$

Actual tree transpiration $\left(E_{\mathrm{p}}\right)$ was measured placing the butt of each excised tree in a reservoir of water filled with $0.05 \mathrm{~mol} \mathrm{l}^{-1} \mathrm{KCl}$ solution. The reservoir was refilled to a constant level immediately after each heat pulse was fired, which allowed us precise quantification of $E_{\mathrm{p}}$ every half hour. Trees were allowed to transpire for 48 hours. The obtained $E_{\mathrm{p}}$ values, together with simultaneous measurements of micrometeorological variables over the tree, were used to calculate reliable values of canopy conductance by inverting the P-M equation $\left(G_{\mathrm{c}}\right)$. Leaf gas exchange measurements were made with a portable photosynthesis system (LI-6400, LI-COR, Lincoln, NE) to determine stomatal conductance $\left(g_{\mathrm{s}}\right)$ every 2 hours from dawn to sunset, in 16 healthy current-year leaves located at positions all around the canopy. From those measurements we derived independent values of canopy conductance for each excised tree $\left(g_{\mathrm{c}} \approx \hat{g}_{\mathrm{s}}\right)$. Total leaf area was estimated at the end of the experiment by weighting all the leaves of each tree. Previously a correlation was found between leaf area and weight. 


\section{RESULTS AND DISCUSSION}

There was a good agreement between $g_{\mathrm{c}}$ calculated from leaf gas exchange and $G_{\mathrm{c}}$ calculated from inversion of P-M equation of $E_{\mathrm{p}}$ (Fig. 1). The success of this correlation is related to the comprehensive sampling of leaf gas exchange throughout the whole crown of the tree, considering all orientations and positions within the crown, as well as the accurate measurement of the micrometeorological variables influencing each studied tree. A good correlation between $G_{\mathrm{c}}$ and $g_{\mathrm{c}}$ is important for our purposes, since it allows us to use a sap-flow-independent estimate of $G_{\mathrm{c}}$, which can be related to $t_{\mathrm{z}}$ values. Figures 2,3 and 4 show the correlation between equation [3] and $g_{c}$ for olive, plum and orange, respectively. A good correlation between both variables was found in olive, not only in the outer sapwood at $5 \mathrm{~mm}$ from the cambium, but also at 15, 25 and $40 \mathrm{~mm}$. In plum, high values of $g_{\mathrm{s}}$ were recorded early in the morning, being the values much lower for the rest of the day, which split $g_{\mathrm{c}}$ into two clearly differentiated groups. This led to less significant correlations between $1 /\left(t_{\mathrm{z}}\right.$ VPD) and $g_{\mathrm{c}}$ than in olive (Fig. 3), although still reasonably good. In orange, however, only $t_{\mathrm{z}}$ in the outer sapwood showed significant correlation with $g_{\mathrm{c}}$ (Fig. 4). For the three studied species, the highest correlation coefficients were obtained in olive. This is not surprising, since Equation [3] requires a good coupling of the canopy to the atmosphere. Of the three studied species, the olive tree is expected to be the best coupled to the atmosphere, due to the small size of its leaves and the low density of its foliage (Moreno et al., 1996; Tognetti et al., 2005).

In conclusion, our results show that the values of $t_{\mathrm{z}}$ obtained with the CHP technique can be used to infer the dynamics of the canopy conductance. This is better achieved in species highly coupled to the atmosphere, such as olive, with small leaves, low leaf density crowns and heterogeneous canopies. This means that we might be able to monitor canopy conductance automatically and in continuous, in trees growing in the field. This has a remarkable potential, since $g_{\mathrm{s}}$ is one of the best indicators of water stress in plants, having been proposed as a good indicator for irrigation scheduling in fruit tree orchards (Jones, 2004). Moreover, $g_{\mathrm{s}}$ has been reported to be the ideal reference parameter to study the down-regulation of photoysnthesis under drought conditions (Medrano et al., 2002), which makes the technique proposed in this work interesting for physiological studies. Although $G_{\mathrm{c}}$ has been estimated many times before from sap flow measurements by inverting the P-M equation, the novelty of our results lies in the use of a single point measurement of temperature to predict the dynamics of stomata. Future work should be conducted to understand the seasonal reduction in $G_{\mathrm{c}}$ and its relationship with changes in the sap flow profile.

\section{ACKNOWLEDGEMENTS}

This work was financed by the Dirección General de Investigación of the Spanish Ministry of Science and Technology (Research Projects AGL2002-04048-CO3-01 and PTR1995-0693-OP-02-01). A. Diaz-Espejo was beneficiary of the Program Ramón y Cajal (M.E.C.). 


\section{Literature Cited}

Čermák, J., Úlehla, J., Kučera, J. and Penka, M. 1982. Sap flow rate and transpiration dynamics in the full-grown oak (Quercus robur L.) in floodplain forest exposed to seasonal floods as related to potential evapotranspiration and tree dimensions. Biol. Plant. 24:446-460.

Čermák, J., Nadezhdina, N., Meiresonne, L., and Ceulemans, R. 2008. Scots pine root distribution derived from radial sap flow patterns in stems of large leaning trees. Plant Soil 305:61-75.

Dye, P.J., Olbrich, B.W. and Poulter, A.G. 1991. The influence of growth rings in Pinus patula on heat pulse velocity and sap flow measurements. J. Exp. Bot. 42:867-870.

Fernández, J.E., M.J. Palomo, A. Díaz-Espejo, B.E. Clothier, S.R. Green, I.F. Girón and F. Moreno. 2001. Heat-pulse measurements of sap flow in olives for automating irrigation: tests, root flow and diagnostics of water stress. Agric. Water Manage. 51:99-123.

Fernández, J.E., Durán, P.J., Palomo, M.J., Diaz-Espejo, A. and Chamorro, V. 2006. Calibration of sap flow estimated by the compensation heat pulse method in olive, plum and orange trees: relationships with xylem anatomy. Tree Phyisol. 26:719-728.

Fiora, A. and Cescatti, A. 2008. Diurnal and seasonal variability in radial distribution of sap flux density: implications for estimating stand transpiration. Tree Physiol. 26:1217-1225.

Ford, C.R., McGuire, M.A., Mitchell, R.J. and Teskey, R.O. 2004. Assessing variation in the radial profile of sap flux density in Pinus species and its effect on daily water use. Tree Physiol. 24:241-249.

Green, S.R., Clothier, B.E. and Jardine, B. 2003. Theory and practical application of heat-pulse to measure sap flow. Agron. J. 95:1371-1379.

Jones, H.G. 1992. "Plants and Microclimate, 2 Edn". Cambridge University Press, Cambridge, Massachusetts.

Jones, H.G. 2004. Irrigation scheduling: advantages and pitfalls of plant-based methods. J. Exp. Bot. 55:2427-2436.

Medrano, H., Escalona, J.M., Bota, J., Gulías, J. and Flexas, J. 2002. Regulation of photosynthesis of $\mathrm{C}_{3}$ plants in response to progressive drought: the interest of stomatal conductance as a reference parameter. Ann. Bot. 89:895-905.

Moreno, F., Fernández, J.E., Clothier, B.E. and Green, S.R. 1996. Transpiration and root water uptake by olive trees. Plant Soil 184:85-96.

Nadezhdina, N., Nadezhdin, V., Ferreira, M.I. and Pitacco A. 2007. Variability with xylem depth in sap flow in trunks and branches of mature olive trees. Tree Physiol. 27:105-113.

Poyatos R., Čermák J. and Llorens P. 2007. Variation in the radial patterns of sap flux density in pubescent oak (Quercus pubescens) and its implications for tree and stand transpiration measurements. Tree Physiol. 27:537-548.

Swanson, R.H. 1965. Seasonal course of transpiration of lodgepole pine and Engelmann spruce. In: Proc. Internat. Symp. on Forest Hydrology, pp 417-432. Pennsylvania St. Univ.

Tateishi, M., Kumagai, T., Utsumi, Y., Umebayashi, T., Shiiba, Y., Inoue, K., Kaji, K., Cho K. and Otsuki K. 2008. Spatial variations in xylem sap flux density in evergreen oak trees with radial-porous wood: comparisons with anatomical observations. Trees 22:23-30.

Tognetti, R., d'Andria, R., Morelli, G. and Alvino, A. 2005. The effect of deficit irrigation on seasonal variations of plant water use in Olea europaea L. Plant Soil 273:139-155. 


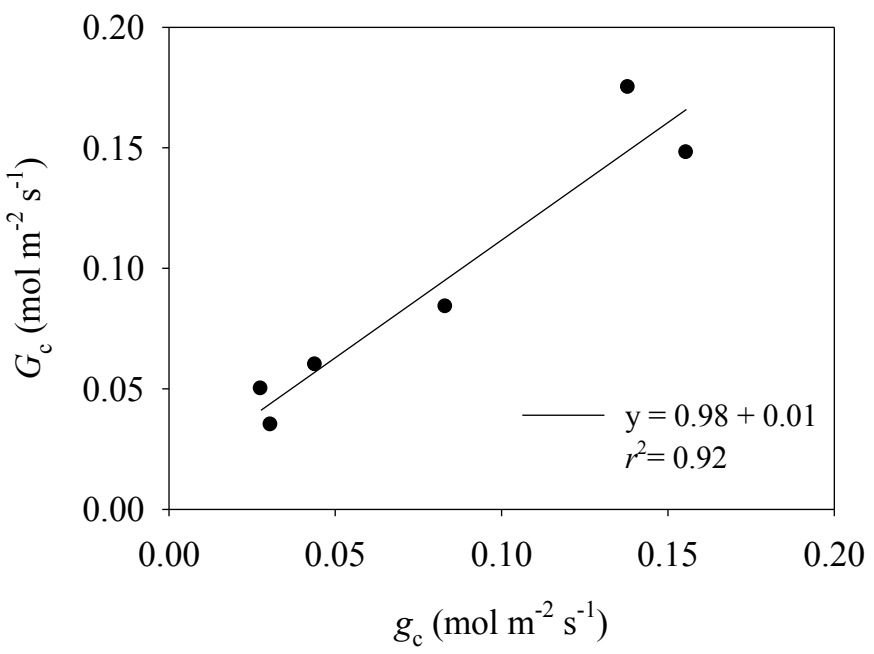

Fig. 1. Relationship between canopy conductance $\left(G_{\mathrm{c}}\right)$ calculated by inverting the equation of Penman-Monteith and using for transpiration the actual values measured in the reservoir of water (see text for details) and canopy conductance calculated as the average of 20 measurements of stomatal conductance troughout the crown of the tree $\left(g_{\mathrm{c}}\right)$.

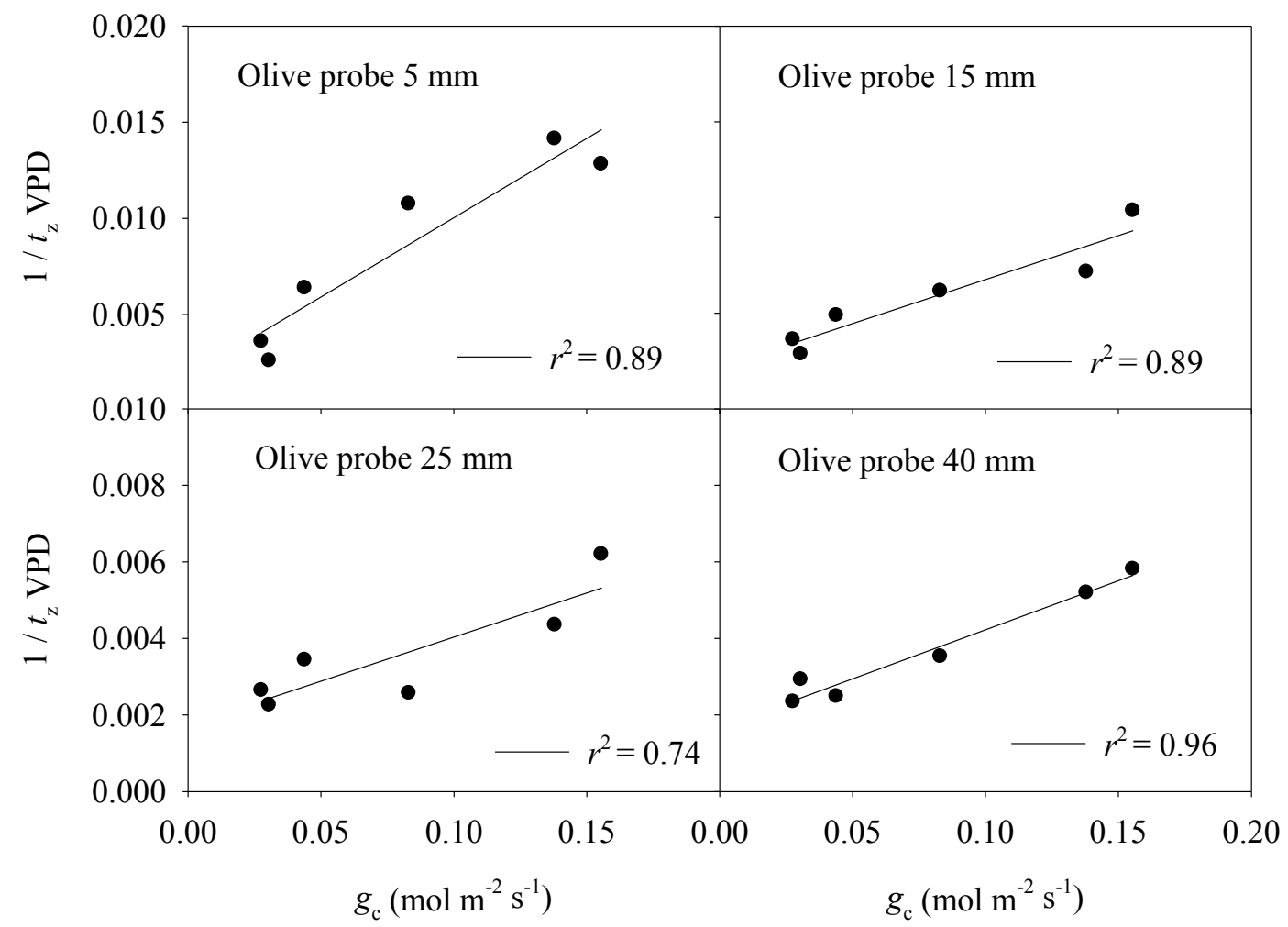

Fig. 2. Relationship between the index $1 /\left(t_{\mathrm{z}} \mathrm{VPD}\right)$ and canopy conductance $\left(g_{\mathrm{c}}\right)$ calculated from leaf gas exchange after 20 measurements throughout the tree crown in olive tree. $t_{\mathrm{z}}$ is the time delay for the temperature at points downstream and upstream from the heater and VPD is the vapour pressure deficit of air. 


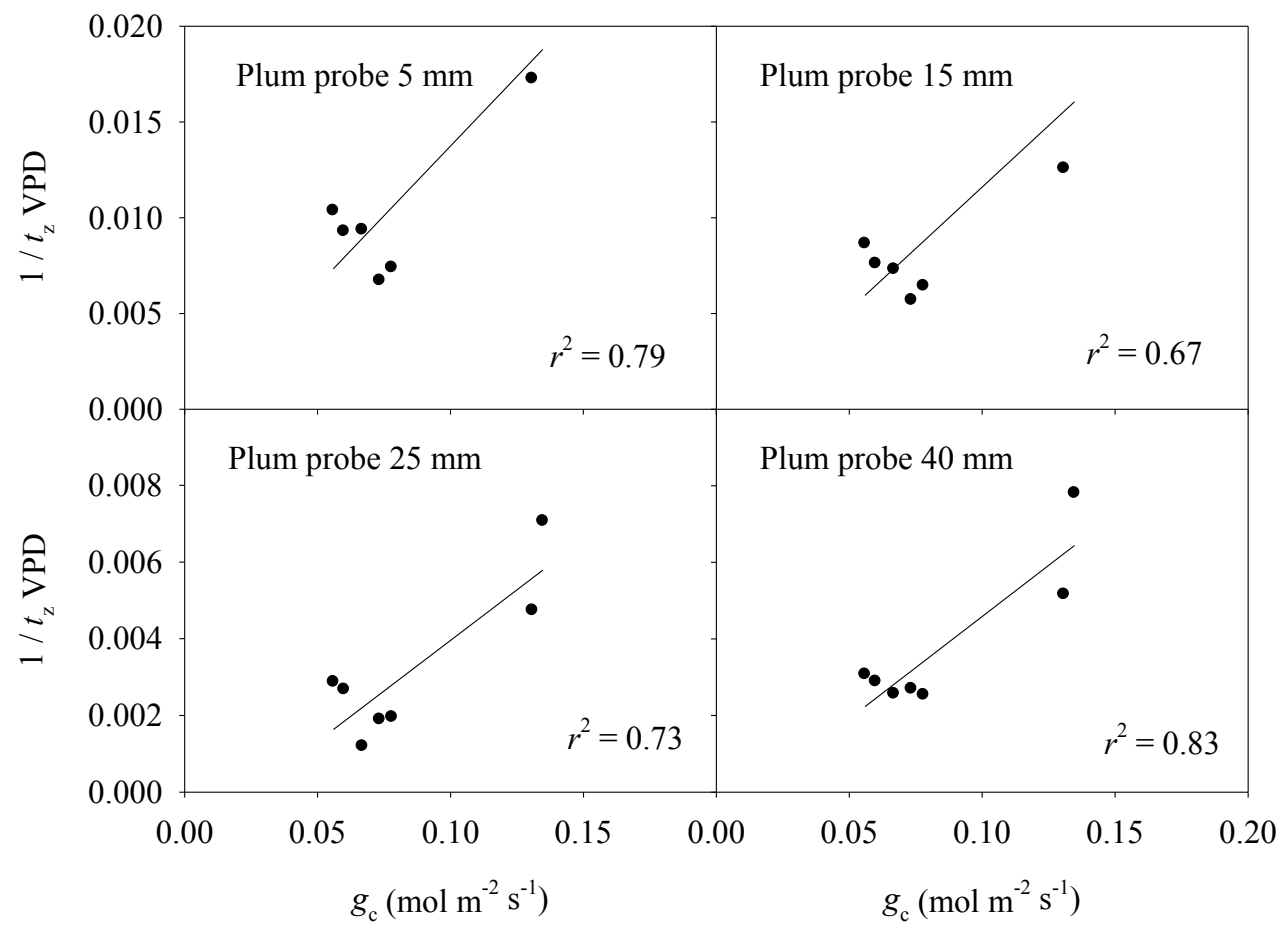

Fig. 3. The same as in Fig. 2, but for the plum tree.

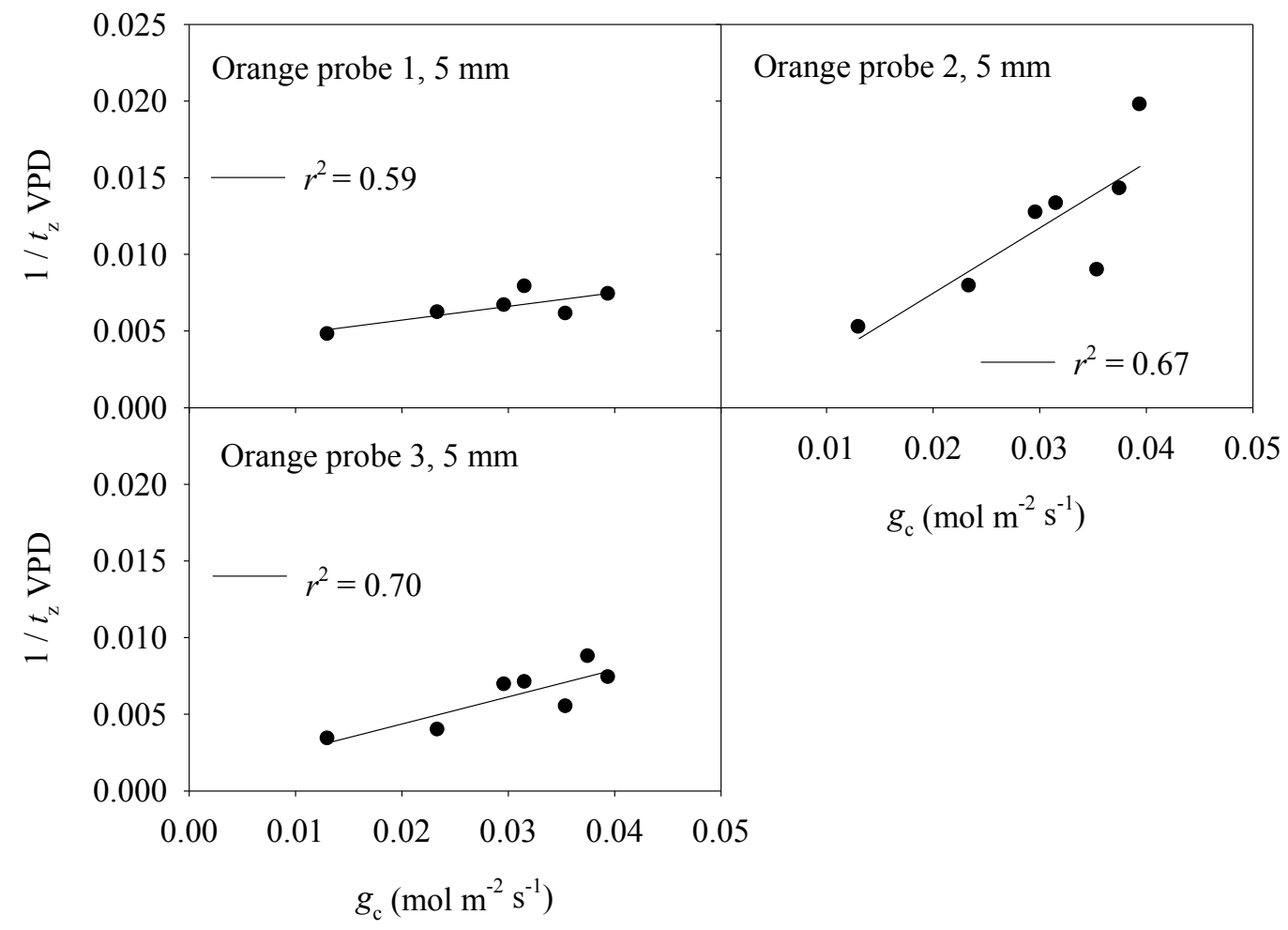

Fig. 4. The same as in Fig. 2, but for the orange tree. 